\title{
A "NOVA" HISTORIOGRAFIA BRASILEIRA
}

\author{
Margareth Rago
}

O Brasil é um país bastante estranho e, freqüentemente, os brasileiros afirmam que aqui tudo pode acontecer. Paraíso e inferno, extrema cordialidade e acentuada violência, riqueza ostensiva e altos indices de miséria, população branca e negra, shoppings centers e favelas, tradição e modernidade, os extremos, enfim, convivem lado a lado, sem provocar maiores surpresas nos seus habitantes. Muitas décadas atrás, um dos mais importantes historiadores brasileiros, Sérgio Buarque de Holanda (1994) afirmou, ao interpretar a história do País desde os inícios da colonização portuguesa, que "somos uns desterrados em nossa terra", referindo-se à maneira pela qual mantemos vínculos frouxos com o passado e as tradições, apesar da extrema afetividade que nos caracteriza.

A complexidade desse universo social aparece quando se tenta mapear a produção cultural brasileira e quando se procura visualizar as tendências ideológicas, politicas e intelectuais que têm marcado o pensamento social no País. Em relação à produção historiográfica mais recente, vale considerar que, a despeito da violenta repressão cultural imposta pela ditadura militar ao longo dos anos 60 e, especialmente, durante a primeira metade dos anos 70, esta década irrompeu trazendo uma grande expansão dos estudos históricos, das pesquisas e publicações de livros, artigos e revistas, impulsionada pela criação dos inúmeros cursos de pós-graduação no País, pelo próprio crescimento do mercado editorial $\mathrm{e}$, não menos, pela intensa pressão da resistência politica organizada, formal e informalmente. Ainda que sob forte abafamento político no Pais, vivemos, ao mesmo tempo e contraditoriamente, um período de florescimento cultural e intelectual em muitos campos, como na música e no teatro, o que se explica, em grande parte, pelo próprio crescimento urbano-industrial, pela expansão do mercado editorial, publicitário e artístico, pelo desenvolvimento das telecomunicações em todo o Pais e, especialmente, pelo relativo fortalecimento econômico das camadas médias.

Margareth Rago é professora no Departamento de Histónia do Instituto de Filosofra e Ciências Fumanas da UNICAMP. 
Além disso, novos grupos sociais, étnicos e sexuais passaram a participar da vida pública, trazendo suas questões e reivindicações e, ao mesmo tempo, ampliando as formas culturais e estéticas de consumo. As mulheres, principalmente, entraram agressivamente no mercado, participando dos cursos nas universidades, nas escolas e em outras instituições, enquanto o movimento feminista levou grande número às praças públicas, exigindo novos direitos sociais e sexuais; os negros colocaram suas demandas na agenda pública, enquanto o movimento operário se reorganizava nos grandes centros industriais e propunha a criação de um importante partido político de massas; os jovens, entre os quais muitos estudantes, passaram a compor um contingente politico expressivo (Stepan, 1988).

$\mathrm{O}$ desenvolvimento de diferentes áreas de estudo e a sofisticação das pesquisas elaboradas tornam complexa a tarefa de mapear as diversas tendências históricas que se entrecruzam no País, marcadas por uma grande variedade e riqueza, desde então. Das questões femininas e do gênero à masculinidade, da sexualidade às relações raciais, da história do público ao privado, da ciência à religiosidade e à magia, da cultura erudita à cultura popular e à mídia, da história social à história cultural, assistimos a uma crescente produção acadêmica, criativa, instigante e polêmica, nas últimas décadas.

De modo geral, essa produção acadêmica procura acompanhar e atualizar-se com os desenvolvimentos teóricos e temáticos que se produzem no exterior, em especial, na França, Inglaterra, Itália e nos Estados Unidos, de onde vêm nossas principais referências teóricas, metodológicas e temáticas. Contudo, também fica clara a preocupação de trabalharem-se as especificidades locais das experiências históricas tal qual se constituem no Pais, nos diferentes estados, cidades e municípios e outras regiōes, diferindo radicalmente daquelas vivenciadas em outros contextos históricos.

\section{A RENOVAÇÃO MARXISTA E A "HISTORIOGRAFIA DA REVOLUÇÃO"}

A explosão de uma expressiva produção historiográfica brasileira ocorre, ainda, num momento em que se tornam visíveis os sinais de esgotamento do marxismo como modelo privilegiado de interpretação do passado. Das primeiras análises marxistas que procuravam definir, inicialmente de maneira bastante mecanicista, posteriormente de modo mais sofisticado, as estruturas socioeconômicas e os modos de produção exis- 
tentes no País passou-se, nos anos 70, a discutir o universo mental e as ideologias presentes nas análises históricas da "realidade brasileira". Em 1977, Carlos Guilherme Mota publica o conhecido Ideologia da cultura brasileira (1933-1974) (1977), um dos raros estudos destinados a analisar, numa perspectiva assumidamente marxista, as tendências ideológicas da produção cultural brasileira ao longo de várias décadas. Concomitante ao estudo de Fernando Novaes, Portugal e Brasil nos quadros do antigo sistema colonial_(1978), voltado para a compreensão das estruturas econômicas predominantes no Brasil Colônia e ao estudo das formas de inserção da atividade produtiva no País nos quadros do sistema econômico capitalista europeu, o estudo de Mota desloca o foco de atenção do campo econômico para a dimensão ideológica do universo da cultura brasileira, mantendo o eixo explicativo na definição da estrutura socioeconômica, tal como fora definida pelos trabalhos da famosa Escola Paulista de Sociologia, na qual atuavam sociólogos como Florestan Fernandes, Azis Simão e Fernando Henrique Cardoso.

Vários estudos orientaram-se nessa direção, privilegiando o estudo das ideologias constitutivas tanto dos movimentos sociais do século XIX, a exemplo da Revolução Praieira, estudada por Isabel Marson, quanto do pensamento social autoritário, como o de Azevedo Amaral, discutido por Adalberto Marson, e ainda veiculada pelos jornais de grande circulação, como no caso dos estudos de Arnaldo Contier e Maria Helena Capelato. ${ }^{2}$ Numa perspectiva marxista bastante sofisticada, esses trabalhos detêm-se na complexidade da análise da ideologia, apontando para sua dimensão instituinte, mais do que reflexiva.

$\mathrm{Na}$ virada da década, surgia, também a partir do centro paulista, outro trabalho renovador, focalizando um momento histórico tradicionalmente consagrado na narrativa histórica brasileira, a Revolução de Trinta. Refiro-me ao Silencio dos vencidos, de Edgar de Decca (1981). Mesmo que localizado num campo historiográfico de inspiração gramsciana, o estudo apontava para os posteriores desdobramentos conceituais realizados em nossa historiografia, a partir da incorporação da análise arqueo-genealógica do discurso proposta por Michel Foucault e das discussões levantadas por Walter Benjamin (1982), nas Teses sobre filosofia da história.

Questionando a temporalidade que localiza uma profunda ruptura na história do Brasil no ano de 1930, o autor procura evidenciar como se constitui o imaginário da Revolução de Trinta, através do silenciamento do conflito capital/trabalho e da produção do silêncio da classe operária, no final dos anos 20 , por uma violenta repressão política. Busca-se, 
neste estudo, não exatamente trazer a voz dos vencidos para o campo da história, mas desvendar os mecanismos discursivos através dos quais se processa o silenciamento dos perdedores da luta politica em torno dos acontecimentos políticos de 1930, definidos como Revolução de Trinta. $O$ autor analisa a produção do campo discursivo a partir do qual se estrutura a memória e a historiografia da Revolução de Trinta, possibilitada pela vitória do discurso do vencedor e da constituição de sua memória particular e excludente como memória oficial e objetiva. Aqui, Decca aponta para a produção da exclusão nas formações discursivas, como sofisticada estratégia da dominação burguesa.

\section{A HISTÓRLA SOCLAL E A EMERGÊNCIA DO SUJEITO}

Este estudo marcou um momento de grandes mudanças c de acelerada arrancada da produção historiográfica, que se seguiu ao encontro das propostas extremamente renovadoras de E. P. Thompson (1988), trazendo não só um novo conceito de classes sociais, mas toda uma ênfase nos aspectos culturais e subjetivos antes ignorados. Ao lado de outros conhecidos historiadores marxistas reunidos em torno das propostas da Social History anglo-americana, o historiador ingles reforça a ruptura com a produção maxxista anterior e realiza uma instigante renovação conceitual no interior deste campo epistemológico: num primeiro momento, ao denunciar o estruturalismo da produção marxista anterior, predominante nos anos 60 e 70, em que os sujcitos quase não aparecem, ou aparecem apenas determinados, sem ação, inertes e sem rosto, definidos por sua inserção na infra-estrutura socioeconômica. Reivindicando a presença ativa dos sujeitos políticos, a ação social e a interferência criativa dos agentes históricos, o historiador inglês afirma que "as classes se fazem tanto quanto são feitas" e, por seu lado, contribui para a crítica do sujeito universal, tal qual é construída pela produção historiográfica. Seu livro, A formação da classe trabalhadora na Inglaterra, publicado inicialmente na década de 60 , é traduzido em meados dos anos 80 , no Brasil, conquistando um grande sucesso nacional.

Num segundo momento, a revolução thompsoniana se faz sentir na maneira pela qual o historiador inglês propõe uma inversão na leitura dos processos históricos, a exemplo da Revolução Industrial, vista como efeito mais do que como ponto de partida. Atentando para as transformações na forma de representação do tempo, que de tempo da natureza passa a ser percebido como tempo do mercado, entre os séculos XIII e XVII, 
Thompson (1979) analisa a constituição de um novo imaginário social que permite a difusão das inovações tecnológicas e da própria industrialização na Inglaterra no século seguinte. Assim, ao contrário do tradicional procedimento teórico-metodológico que assume a infra-estrutura econômica como lugar de inteligibilidade da história, o historiador inglês busca no imaginário a condição de possibilidade da mudança socioeconômica e tecnológica.

Cornelius Castoriadis (1986), que também passa a ser amplamente traduzido e divulgado no País, fazendo a crítica da burocracia de Estado, aponta para os limites do conceito de ideologia e propõe o de imaginário social, ampliando cnormemente as possibilidades de construção do conhecimento histórico. Na verdade, cada vez mais os historiadores se despedem das formas estruturadas e estritamente racionais do pensamento ou das formas organizadas e institucionais da ação politica para buscarem as manifestações incontroladas, emotivas, instintivas da subjetividade, ou ainda, as formas informais e anárquicas da ação política coletiva. Também aqui, os dois autores se tornam importantes referências teóricas e políticas, ao chamarem a atenção para o revolucionarismo de outras práticas políticas, a exemplo da liderada pelos luditas, ou destruidores de máquinas da primeira fase da Revolução Industrial inglesa, questionando frontalmente categorias como as de "rebeldes primitivos" ou de movimentos pré-políticos, outrora enunciadas por Eric Hobsbawm e amplamente aceitas nas análises acadêmicas. ${ }^{3}$

Vários estudos inspiraram-se nesses debates, como Trabalho urbano e conflito indusirial, de Boris Fausto (Difel, 1977), História do trabalho e da indústria no Brasil, de Francisco Foot Hardman e Victor Leonardi (Global, 1982), Nem pátria, nem paträo, de Francisco Foot Hardman (Brasiliense, 1983), Do cabaré ao lar. A utopia da cidade disciplinar, de Margareth Rago (Paz e Terra, 1985), Trabalho, lar e botequim, de Sidney Chaloub (Brasiliense, 1986), A vida fora das fábricas, de Maria Auxiliadora Guzzo Decca (Paz e Terra, 1987), entre outros.

De modo geral, esses trabalhos analisam a condição operária no cotidiano da vida social, dentro e fora dos muros da fábrica, percebendo os mecanismos de controle e disciplinarização dos trabalhadores, que se difundem nas primeiras décadas do século, num momento de intensa industrialização e urbanização das cidades. Contudo, enquanto os primeiros atentam para as tendências políticas que dominam o movimento operário, como os anarquistas, socialistas e posteriormente os comunistas, destacando sua importância na formação da classe operária no País, os estudos de Chaloub e Guzzo buscam os trabalhadores fora do campo da 
militância, dando maior ênfase às formas cotidianas da vida social. Já Francisco Foot Hardman, em Nem pátria nem patrão (Brasiliense, 1884), revela, num trabalho bastante inovador, o universo cultural, artístico e literário construído pelos trabalhadores e militantes, entre anarquistas e anarcossindicalistas, nas primeiras décadas do século.

Progressivamente, outros sujeitos sociais foram incluídos nos estudos históricos, eliminando-se a hierarquia dos temas e as problematizações privilegiadas. Mulheres, negros, escravos, homossexuais, prisioneiros, loucos e crianças constituiram uma ampla gama de excluídos, que reclamaram seu lugar na história social do País. É de se notar que a curva tendeu a progredir dos setores mais estigmatizados e socialmente excluídos até, mais recentemente, os grupos sociais ou profissionais economicamente melhor situados, como os aristocratas do café, por exemplo, cuja história, contudo, apenas começa a ser contada (Maluf, 1995).

A enorme ampliação do leque temático e dos sujeitos históricos forçou um alargamento do campo conceitual e acentuou a busca por novas formas de operar o conhecimento. Nesse contexto, outra importante fonte de renovação veio da redescoberta da Escola dos Annales, obscurecida pela produção marxista desde o final dos anos 60 , e da Nova História, que encanta com seus novos temas e abordagens, sobretudo ao longo dos anos 80 (Dosse, 1992; Burke, 1991). Dos instintos aos sentimentos, do medo ao amor, do cheiro às lágrimas, entre a mentalidade e a sensibilidade, pensadas nas múltiplas temporalidades existentes na "Ionga duração", os novos temas revelam um vasto campo de pesquisas inexploradas. Ao contrário das mudanças revolucionárias, da ansiosa busca marxista da luta de classes e da Revolução, passa-se paulatinamente a olhar para as permanências estruturais, para as continuidades existentes ao longo dos processos temporais, o que ajuda, em certa medida, a explicar as falências das propostas transformadoras. Duvida-se crescentemente da possibilidade de um conhecimento objetivo, enquanto a dimensão subjetiva e o campo simbólico passam a ser avidamente interrogados.

\section{EM BUSCA DA DIFERENÇA}

Embora os próprios temas e conceitos com que operavam os pesquisadores de filiação marxista tenham sofrido uma grande renovação, a abertura dos historiadores para os novos temas, objetos e atores que pressionam pelo "direito à história", resulta em importantes deslocamentos teóricos e impõe a busca de novos conceitos e formas de pensamen- 
to que dêem conta de pensar diferentemente no campo histórico. Nesse movimento, percebe-se que vários dos temas pesquisados - como a história do cotidiano, dos sentimentos e dos afetos, da criança e da família, da prisão e de outras instituições, do corpo e da sexualidade - não são totalmente novos, no entanto, passam a ser renovados através das questões colocadas e das novas interpretações a que são submetidos.

Além disso, na busca de um "pensamento da diferença", Foucault irrompe como um furacão, ao longo dos anos 70, ao lado de outros pensadores como Claude Lefort, Cornelius Castoriadis, Walter Benjamin, provocando amores e ódios, fortes adesões e infinitas contestações, sobretudo dos que reclamam a luta das classes como motor da história. ${ }^{4}$ Subverte irremediavelmente o universo mental e conceitual dos historiadores. Afirmando a positividade do poder, dos micropoderes que engendram individualidades, que produzem o real, classificam os corpos e normatizam os gestos; chamando a atenção para a materialidade do discurso e para sua dimensão de estratégia discursiva e prática instituinte; atentando para os modos de subjetivação e para a cultura de si, o filósofo desloca o sujeito da centralidade que ocupa no pensamento ocidental e abala nossos alicerces. Não podemos mais fazer história tranqüilamente, ou ingenuamente melhor dizendo. Enfim, disse ele:

de que valeria a obstinação do saber se ele assegurasse apenas a aquisição dos conhecimentos e não, de certa maneira, e tanto quanto possivel, o descaminho daquele que conhece? Existem momentos na vida onde a questão de saber se se pode pensar diferentemente do que se pensa e perceber diferentemente do que se vê é indispensável para continuar a olhar ou a refletir. (1984)

Desde então, não podemos mais falar em totalidade histórica, em "realidade objetiva", em determinações fundamentais da infra-estrutura econômica sobre tudo o mais desavisadamente, nem podemos deixar de pensar diferentemente o documento. Nesse momento, nos damos conta de que o historiador trabalha primeiramente com a produção dos discursos, com interpretações, com máscaras sobre máscaras e que a busca da objetividade e de uma suposta essência natural é mais uma ilusão antropológica. Não mais fatos, não mais os objetos e os sujeitos no ponto de partida, mas os discursos e as práticas instituintes produtoras de real, como afirma Paul Veyne. Não apenas a história da razão, mas a da loucura, não apenas a história social dos prisioneiros, mas as formas pelas quais a prisão emerge como forma punitiva considerada verdadeira, ne- 
cessária e universal; não a história da sexuálidade ao longo da história, mas a de uma problemática relação com o sexo, marcada pela emergência de um "dispositivo da sexualidade" no mundo vitoriano, regulando e normatizando os individuos e seus comportamentos: não objetos prontos e acabados evoluindo ao longo da história do progresso e da razão, mas práticas discursivas e não-discursivas constituidoras e instituintes.

Em 1978, é publicado o pioneiro estudo histórico do filósofo Roberto Machado, Danação da norma (Graal, 1978), em que se lê genealogicamente a história do Brasil colonial, percebendo-se aí os primeiros sinais da emergência da sociedade disciplinar. $O$ ano de 1979 assiste à publicação do trabalho histórico do psiquiatra Jurandir Freire Costa, também ex-aluno de Foucault, Ordem médica e norma familiar (Graal, 1979), desvendando o estabelecimento da aliança entre a família o Estado e o poder médico ao longo do século passado. Vale ressaltar que esses trabalhos foram recebidos pelo mundo acadêmico com um sentimento misto de estranhamento pela enorme novidade teórica e de perplexidade, pois, embora de grande qualidade em termos de pesquisa histórica e inovação temática, haviam sido produzidos fora da comunidade dos historiadores. Um novo olhar se produzia sobre a história do Brasil, apresentando uma documentação pouco conhecida pelos historiadores: teses médicas da Faculdade de Medicina da Bahia e do Rio de Janeiro, ou documentos de prisões, hospitais e asilos e regulamentos escolares. Um novo campo se constituía, das margens para o centro das pesquisas históricas, evidenciando o quanto o discurso marxista de interpretação histórica, atento aos modos de produção e estruturas sociais, havia envelhecido. Aqui não apenas emergia a temática da normatização e medicalização da sociedade, como inúmeras fontes documentais, absolutamente inexploradas e despercebidas pelos historiadores, vinham à tona, trazendo espanto e desconforto.

$O$ passo seguinte foi a proliferação dos estudos foucaultianos das relações microfísicas do poder no Brasil, com a publicação de Do cabaré ao lar. A utopia da cidade disciplinar (Paz e Terra, 1985), já citado, $O$ espelho do mundo - Juquery, a história de um asilo (Paz e Terra, 1986), de Maria Clementina P. da Cunha, Sacralização da política, de Alcir Lenharo (Papirus, 1988), e Meretrizes e doutores. Saber médico e prostituição no Rio de Janeiro (Brasiliense, 1989).

Em Do cabaré ao lar, trabalho as formas da disciplinarização da vida social dentro e fora das fábricas, a construção do mito do amor materno, o seqüiestro da criança no interior das escolas e a desodorização do espaço urbano, como temas destacados para pensar a projeção bur- 
guesa sobre as classes trabalhadoras, nas décadas iniciais do século. Procuro, ainda, perceber como os dominados resistiram ao encontrar no anarquismo a linguagem política capaz de lhes permitir formular um projeto radical de transformação social. Assim, os anarquistas, como tendência dominante do movimento opcrário brasileiro no periodo, apontam para a autogestão do trabalho nas fábricas, para a construção de uma nova família, baseada em uniões livres, defendendo a emancipação das mulheres e a organização libertária da cidade.

Alcir Lenharo focaliza o discurso veiculado durante o período ditatorial do Estado Novo, no Brasil, entre 1939 e 1945, apontando para as formas de construção do líder político Getúlio Vargas, tido ainda hoje como "pai dos pobres" e, não raro, reverenciado pela memória oficial e pelo senso comum por seu paternalismo. Numa perspectiva bastante inovadora, trabalha a disciplinarização do corpo pelo poder politico, através dos programas de educação e propaganda lançados à juventude e também a partir da construção da política como espaço sacralizado.

Mais recentemente, outro livro marca fortemente a presença de Foucault na historiografia brasileira. Trata-se de $A$ invenção do nordeste e outras artes, de Durval de Albuquerque (Cortez, no prelo), que apresenta o nascimento dessa importante região brasileira, como configuração discursiva e política, associada à questão da seca, tal como foi formulada pelas elites regionais. Para além dos estudos sobre as formas de normatização dos indivíduos, esse trabalho aponta para as relações de poder constitutivas dos discursos instauradores dos parâmetros geográficos, históricos e regionais que difundem e cristalizam, no País, a imagem do Nordeste como lugar do atraso rural, do calor abafado e da violência.

$\mathrm{Na}$ verdade, não apenas a microfísica do poder foi lida a partir das formulações foucaultianas. Já em suas últimas obras, o filósofo deslocava suas análises chamando a atenção para as questões éticas e estéticas da subjetivação. Fundamentando-se nele e em outros autores pósmodernos, como Deleuze e Guattari, os historiadores procuraram historicizar as práticas desejantes e os processos de desterritorialização vivenciados na modernidade brasileira. Nesse sentido, procuro pensar as formas de subjetivação presentes na cultura do bordel, em Os prazeres da noite. Prostituição e códigos da sexualidade feminina em São Paulo. (1890-1930) (Paz e Terra, 1991). Para além da medicalização das sexualidades insubmissas e do controle sobre o corpo feminino, trata-se, nesta perspectiva, de explorar as formas alternativas de sociabilidade e de subjetivação vivenciadas na experiência do desejo, num momento de inten- 
sa modernização da cidade. Nesta direção, o recente estudo de Antonio Paulo Benatti, $O$ centro e as margens. Prostituição e vida boêmia em Londrina, 1930-1960 (Curitiba: Aos Quatro Ventos, 1997), amplia a dimensão da análise das sociabilidades nômades e periféricas, apoiado em ampla pesquisa documental, num momento particularmente importante da vida da cidade de Londrina, no estado do Paraná.

Incorporar a dimensão da produção da subjetividade como espaço de análise tem sido um enorme desafio para o historiador, acostumado desde muito a trabalhar com figuras sociais e sexuais bem definidas, ou com fenômenos antes considerados acabados e nitidamente desenhados. Na verdade, as discussões em torno da história das mulheres, do corpo e da sexualidade propiciam toda uma série de transformações temáticas e teóricas, forçando-nos a buscar novas frentes conceituais, mais elásticas e flexíveis.

\section{HISTÓRIAS DE EVA E ADÃo}

A cntrada massiva das mulheres no mercado de trabalho e a crescente pressão do movimento feminista afetam profundamente os estudos históricos também no Brasil. Contudo, a visibilidade que ganham as mulheres como agentes históricos, a partir dos anos 70, com o trabalho de Heleicth Saffioti, Mito e realidade: a mulher na sociedade de classes, ocorre inicialmente a partir do padrão masculino da história social, extremamente preocupada com a denúncia das formas da exploração capitalista (Rago, 1991). Em outros termos, isto significa dizer que houve uma acentuada preocupação em criticar as formas da opressão patronal sobre as trabalhadoras, o que resultou em grande parte no reforço da vitimização da mulher.

$\mathrm{Na}$ contracorrente dessas interpretações, os anos 80 assistiram à produção de vários estudos que procuravam desconstruir a figura da passividade feminina, revelando as múltiplas formas de resistência social e atuação política das mulheres tanto de camadas sociais desfavorecidas quanto das camadas médias e das elites. A "brazilianista" Juhne Hahner publica A mulher brasileira e suas lutas sociais e politicas: 1850-1937 (Brasiliense, 1981), enquanto Maria Odila L. da Silva Dias apresenta, em Quotidiano e poder em São Paulo no século XIX (Brasiliense, 1984), as estratégias informais criadas pelas mulheres pobres na luta pela sobrevivência material na cidade de São Paulo, nos inícios do século XIX. Pela primcira vez, doceiras, Iavadeiras, prostitutas, empregadas domés- 
ticas, mulheres pobres e abandonadas, a maioria exercendo a função de chefe de família, faziam sua aparição num livro de história, valorizadas pelas soluções inteligentes que encontravam para as pesadas tarefas da cotidianidade. Neste mesmo ano, vale lembrar, Miriam Moreira Leite (1984; Alves, 1980) traz à luz a vida de uma militante feminista libertária, Maria Lacerda de Moura, cuja atuação ocorre paralela ao feminismo liberal liderado por Bertha Lutz.

Esse quadro de participação das mulheres ampliou-se consideravelmente com a explosão dos temas femininos da Nouvelle Histoire, como bruxaria, prostituição, loucura, aborto, parto, maternidade, saúde, sexualidade, a história das emoções c dos sentimentos, entre outros. Novamente, destaca-se o trabalho de outra "brazilianista", Susan Besse, que produz uma importante tese de doutoramento na Universidade de Yale, orientada pela professora Emilia Viotti da Costa, sobre a modernização das desigualdades sexuais no Brasil. O livro, publicado no ano passado, ainda não traduzido, intitula-se Restructuring Patriarchy. The modernization of gender inequality in Brazil, 1914-1940 (Chapel Hill and London: The University of North Carolina Press, 1996).

Referenciada pela história das mentalidades, Laura de Melo e Souza escreveu $O$ diabo e a Terra de Santa Cruz. Feitiçaria e Religiosidade popular no Brasil colonial (Companhia das Letras, 1986), no qual analisa os casos de feitiçaria condenados pela Inquisição no Brasil colonial. Ronaldo Vainfas, em Trópicos dos pecados. Moral, sexualidade $e$ Inquisição no Brasil (Campus, 1989), tematiza brilhantemente a história da sexualidade brasileira, mostrando a perseguição da Inquisição às práticas sexuais consideradas condenáveis, enquanto Lígia Bellini, em A coisa obscura. Mulher, sodomia e Inquisição no Brasil colonial (Brasiliense, 1987), privilegia as práticas sexuais das mulheres como alvo de investimento do poder religioso.

Magali Engel, em Meretrizes e doutores: saber médico e prostituição no Rio de Janeiro (Brasiliense, 1989), analisa o discurso médico sobre a sexualidade feminina no Rio de Janeiro. Martha de Abreu Esteves focaliza o discurso jurídico e a resistência feminina em Meninas perdidas. Os populares e o cotidiano do amor no Rio de Janeiro da Belle Époque (Paz e Terra, 1989). Raquel Soihet (1989) analisa a violência urbana exercida contra as mulheres pobres, enquanto Eni de Mesquita (1989), em seus estudos sobre as mulheres e as familias brasileiras, informa sobre as diferentes formas de organização familiar existentes no País e sobre os divórcios solicitados por mulheres. Já Leila Mezan (1993), combinando os ensinamentos da história social e da Nouvelle Histoire, 
acompanha as reclusas aos conventos dos séculos XVII e XVIII. Mary del Priore (1993) estuda as representações construídas nos discursos médico e religioso sobre a maternidade, também no Brasil colonial. Recentemente, Joana Pedro (1994), que havia estudado as Mulheres honestas e mulheres faladas: uma questão de classe (Florianópolis: Editora da UFSC), envereda por um campo que nos é bastante desconhecido quando historia as práticas de aborto sofridas pelas mulheres em Santa Catarina nas décadas passadas.

Para além das diferentes temáticas e temporalidades, esses estudos feministas cruzam-se pela intenção implícita de questionar o mito da passividade feminina, revclando espaços antes pouco explorados por uma tradição historiográfica essencialmente masculina, preocupada com o espaço público e a política institucional.

E claro que muitos discordarão da divisão sexual dos temas históricos acima proposta, já que há muitas outras dimensões implicadas na ampliação do leque temático, principalmente a crise da "historiografia da Revolução" e a redescoberta da Escola dos Annales. Entretanto, poucos poderão negar que a entrada desses novos temas se faz, em grande parte, pela pressão crescente das mulheres, que invadem as universidades e criam seus próprios núcleos de estudo e pesquisa, a partir dos anos 70. Feministas assumidas ou não, as mulheres forçam a inclusão dos temas que falam de si, que contam sua própria história e de suas antepassadas, que permitem entender as origens de muitas crenças e valores, de muitas práticas sociais freqüentemente opressivas e de inúmeras formas de estigmatização. De certo modo, o passado já nada nos dizia e precisava ser re-interrogado a partir de novos olhares e problematizaçõcs, através de outras categorias interpretativas, criadas fora da estrutura falocêntrica especular.

A descoberta da origem da "mãc moderna" a partir do modelo rousseaunista, proposta por Elisabeth Badinter, por exemplo, foi fundamental para se reforçar não só o questionamento do padrão de maternidade que havia vigorado inquestionável até os anos 60 como reforçar a luta feminista pela conquista de novos direitos. A genealogia dos conceitos da prostituição, da homossexualidade e da perversão sexual, entre outros, foi extremamente importante enquanto reforçava a desconstrução prática das inúmeras formas de normatização. ${ }^{5}$ A história do corpo feminino trouxe à luz as inúmeras construções estigmatizadoras e misóginas do poder médi$c o$, para o qual a constituição fisica da mulher por si só inviabilizaria sua entrada no mundo dos negócios e da política. ${ }^{6} \mathrm{O}$ questionamento das mitologias científicas sobre sua suposta natureza, sobre a questão da mater- 
nidade, do corpo e da sexualidade, foi fundamental $\mathrm{cm}$ termos da legitimação das transformações libertadoras em curso.

O campo das experiências históricas consideradas dignas de serem

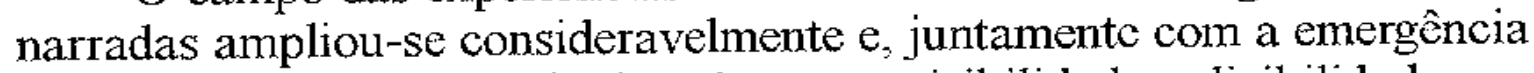
dos novos tcmas de estudo, isto é, com a visibilidade e dizibilidade que ganharam inúmeras práticas sociais, culturais, religiosas, antes silenciadas, novos sujeitos femininos foram incluídos no discurso histórico, partindo-se inicialmente das trabalhadoras e militantes, para incluir-se, em seguida, as bruxas, as prostitutas, as freiras, as parteiras, as loucas, as domésticas, as professoras, entre outras. A ampliação do conceito de cidadania e o direito à história e à memória não se processavam apenas no campo dos movimentos sociais, incorporavam-se no discurso, ou melhor, no próprio âmbito do processo da produção do conhecimento.

Para tanto, novos conceitos e categorias tiveram de ser introduzidos a partir das perguntas levantadas pelo feminismo e pelos deslocamentos teóricos e práticos provocados. Por que se privilegiavam os acontecimentos da esfera pública e não os constitutivos de uma história da vida privada? Por que se desprezava a cozinha em relação à sala, e a casa em relação à rua? Onde uma história dos segredos, das formas de circulação e comunicação femininas, das fofocas, das redes interativas construidas nas margens, igualmente fundamentais para a construção da vida em socicdade? Quais as possibilidades de uma história no feminino? Não apenas a história das mulheres, mas a história contada no registro feminino (Swain, 1995)?

Neste contexto, ficou evidente a precariedade estreiteza do instrumental conceitual disponivel para registrar as práticas sociais que passavam a ser percebidas, embora existentes desde sempre. Como o historiador formado na tradição marxista, especialista na recuperação histórica das lutas sociais e da dominação de classes, falaria das práticas desejantes, com que conceitos poderia construir uma história do amor, da sexualidade, do corpo ou do medo? Como trabalhar a questão da religiosidade e das reações diante da vida e da morte?

No casos dos estudos feministas, o sucesso da categoria do gênero se explica, em grande parte, por ter dado uma resposta interessante ao impasse teórico existente no momento em que se questionava a lógica da identidade e se decretava o eclipse do sujeito (Rago, 1998). Categoria relacional, como observa Joan Scott, encontrou campo extremamente favorável num momento de grande mudança das referências teóricas vigentes nas ciências humanas, e em que a dimensão da cultura passava a ser privilegiada sobre as determinações da sociedade. Assim 
como outras correntes de pensamento, a teoria feminista propunha que se pensasse a construção cultural das diferenças sexuais, negando radicalmente o determinismo natural e biológico. Portanto, a dimensão simbólica, o imaginário social, a construção dos múltiplos sentidos e interpretações, no interior de uma dada cultura, passavam a ser priorizados em relação às explicações econômicas ou políticas.

Em relação aos estudos feministas, vale notar que a categoria do gênero abre a possibilidade da constituição dos estudos sobre a masculinidade num campo teórico e temático radicalmente redimensionado. Após a "revolução feminista" e a conquista da visibilidade feminina, após a constituição da área de pesquisa e estudos feministas, consagrada academicamente em todo o mundo, os homens são chamados a entrar, desta vez, em um novo solo epistêmico. É assim que emergem, com enorme aceitação, os estudos históricos, antropológicos e sociológicos - interdisciplinares - sobre a masculinidade. Cada vez mais, portanto, crescem os estudos sobre as relações de gênero, sobre as mulheres, em particular, ao mesmo tempo em que se constitui uma nova área de estudos sobre os homens, não mais percebidos como sujeitos universais.

Sem dúvida alguma, os resultados das inúmeras perspectivas abertas têm sido dos mais criativos e instigantes. O olhar feminista permite reler a história da colonização no Brasil, no século XVI, a exemplo do que realiza a historiadora Tânia Navarro Swain, desconstruindo as imagens e representações construídas pelos viajantes sobre as formas de organização dos indigenas, sobre a sexualidade das mulheres, supostamente fogosas e promiscuas, instituindo sua falta de moralidade. Num excelente trabalho genealógico, a historiadora revela como os documentos foram apropriados e reinterpretados pela historiografia masculina, através de conceitos misóginos, cristalizando-se imagens muito negativas a respeito dos primeiros habitantes da terra, considerados para sempre incivilizados e incapazes de cidadania.

Já Maria Izilda Mattos e Fernando A. Faria (1996), estudando as composições musicais de Lupicínio Rodrigues, a partir da categoria do gênero, descortinam as formas de construção cultural das referências identitárias da feminilidade e da masculinidade, nas décadas de 1940 e 1950 , dominantes até recentemente. A partir da análise das letras de músicas produzidas pelo famoso compositor gaúcho, podem ser visualizadas não apenas as experiências femininas, mas também "seu universo de relações com o mundo masculino", numa proposta bastante enriquecedora e inovadora.

As possibilidades abertas para os estudos históricos pelas teorias 
feministas são inúmeras e profundamente instigantes: da desconstrução dos temas e interpretações masculinos às novas propostas de se falar $f e-$ mininamente das experiências do cotidiano, da micro-história, dos detalhes, do mundo privado, rompendo com as antigas oposições binárias e de dentro, buscando respaldo na Antropologia e na Psicanálise, incorporando a dimensão subjetiva do narrador.

Na historiografia feminista, vale notar, a teoria segue a experiência: esta não é buscada para comprovar aquela, aprioristicamente proposta. Opera-se uma desierarquização dos acontecimentos: todos se tornam passíveis de serem historicizados, e não apenas as ações de determinados sujeitos sociais, sexuais e étnicos das elites econômicas e políticas, ou de outros setores sociais, como o proletariado-masculino-branco, tido como sujeito privilegiado, por longo tempo, na produção acadêmica. Aliás, as práticas passam a ser privilegiadas em relação aos sujeitos sociais, num movimento que me parece bastante democratizador. Assim, e como diria Paul Veyne, o que deve ser privilegiado pelo historiador passa a ser dado pela temática que ele recorta e constrói, e não por um consenso teórico exterior à problemática, como acontecia antes quando se trabalhava com o conceito de modo de produção, por exemplo, ou ainda, quando a preocupação maior com o passado advinha de suas possibilidades em dar respostas à busca da revolução.

\section{CULTURA URBANA E HISTÓRIA CULTURAL}

Os historiadores abrem, ainda, as portas das cidades para suas pesquisas. Do estranhamento provocado pelo surgimento das grandes metrópoles européias, representadas a partir da metáfora do monstro, nos inícios do século XIX, passa-se a discutir os debates em torno das formas de espacialização e planejamento urbano. ${ }^{7}$ Iniciando-se pelos estudos que problematizam o nascimento da "questão urbana" na Europa, novos estudos descobrem as cidades brasileiras, seja a partir da noção de disciplinarização de Foucault, seja a partir da análise da constituição da sensibilidade moderna, apresentada por Benjamin, ao visitar a Paris de Baudelaire. A arquitetura fisica é politizada como "arquitetura da vigilância", ao mesmo tempo em se registra a emergência da sensibilidade moderna, atenta para os novos códigos de sociabilidade que se constituem nas grandes cidades.

Walter Benjamin reforça os deslocamentos teóricos em curso, atentando para a crítica da memória histórica, como memória oficial e hegemôni- 
ca, impelindo-nos para ler o "avesso do avesso", como canta Caetano Veloso, a escovar a história a contrapelo e atentar para a crítica do progresso e da modernidade. A sexta tese de sua Filosofia da história é repetida em muitos cantos do País, em nome da quebra do "silêncio dos vencidos" :

Articular historicamente lo pasado no significa conocerlo "tal y como verdaderamente ha sido". Significa adueñarse de un recuerdo tal y como relumbra en el instante de un peligro. Al materialismo historico le incumbe fijar una imagen del pasado tal y como se le presenta de improviso al sujeto historico en el instante de peligro. El peligro amenza tanto al patrimonio de la tradición al respectivo conformismo que está a punto de subyugarla. El Mesias no viene unicamente como redentor; viene como vencedor del anticristo. el don de encender en lo pasado la chispa de la esperanza sólo es inherente al historiador que está penetrado de lo siguiente: tampoco los muertos estarán seguros ante el enemigo cuando éste venza. Y este enemigo no ha cesado de vencer. (1982, p.180)

Foram vários os estudos que centraram sua atenção nos fenômenos da urbanização em São Paulo, no Rio de Janeiro e em muitas outras cidades do País, entre Porto Alegre, Recife e Belém do Pará. Quase todos esses trabalhos privilegiaram as primeiras décadas do século, momento de intensa modernização e urbanização das cidades, de investimento industrial e de fomento da imigração européia, especialmente no Centro-Sul e Região Sudeste. Os passeios, as modas, os novos perfis urbanos, as novas tecnologias, as soluções urbanísticas, a vida do submundo, a saúde pública e as questões da higiene compuseram um amplo leque de possibilidades temáticas.

Também a partir de uma perspectiva foucaultiana, em especial apropriando-se do conceito de poder disciplinar e das relações saber/poder, procurou-se pensar a constituição da "geografia do poder", destacando as formas invisíveis de esquadrinhamento da população, de individualização dos corpos e de segregação dos pobres na periferia das cidades. No Rio de Janeiro, as reformas do prefeito Pereira Passos foram pensadas a partir das primeiras formulações do Barão de Haussman, que, durante o governo de Napoleão III, dirigiu os trabalhos de remodelação de Paris. Desejo de europeização da cidade, de um lado, preocupação com a higiene pública e o controle social, de outro, os temas privilegiados nos estudos de cultura urbana, a exemplo dos trabalhos de Sérgio Pechman, Lilian Fritsch (1985, p.139-196) e José Murilo de Carvalho (19??) reve- 
lam a trama das relações de poder e dos saberes constituídos pelas elites dominantes em relação às populações ricas e pobres. Mais recentemente, Cidade febril. Cortiços e epidemias na Corte Imperial, de Sidney Chaloub (Companhia das Letras, 1996), discute a remodelação urbana, a higienização e a resistência popular através do episódio da Revolta da Vacina, ocorrida em 1904, no Rio de Janeiro.

Em São Paulo, Nicolau Sevcenko (1992) diversifica a análise inspirando-se, dentre outros autores, em Walter Benjamin para abordar as profundas transformações trazidas na subjetividade contemporânea pela modernização acelerada. Os ritmos urbanos eletrizantes, a agitação da vida social, o surgimento das vanguardas estéticas, a velocidade das máquinas e a agilização dos corpos, a difusão dos esportes, de novas formas de sociabilidade e lazer, nos movimentados anos 20 , são questões centrais inteligentemente captadas em Orfeu extático na metrópole. São Paulo, sociedade e cultura nos frementes anos 20.

Paulatinamente, a cidade se abre ao olhar do historiador, ampliando enormemente o campo de pesquisa: da "arquitetura da vigilância" à ocupação do espaço público pelas mulheres, dos cafés-concertos, cinemas e restaurantes aos hospitais, prisões e cemitérios, o espaço urbano é tematizado em suas múltiplas dimensões e efervescentes atividades. Da constituição da cidade disciplinar, da higienização dos corpos e segregação dos pobres, passa-se a pesquisar o universo cultural, a vida das mulheres e crianças, os espaços boêmios, os diferentes códigos de sociabilidade trazidos pela modernidade, como explica Georg Simmel. Dentre as inúmeras publicações na área, destaca-se o trabalho de José Roberto do Amaral Lapa, A cidade: os cantos e os antros (Edusp, 1996). Nesse estudo sobre a cidade de Campinas, próxima a São Paulo, entre 18501900, revela o impacto da modernização e da imigração, e a constituição de novos espaços de cultura e lazer, para além do processo de higienização implícito na urbanização. As práticas lúdicas, de lazer e festa em inúmeras cidades e estados brasileiros, vêm ganhando visibilidade com a publicação de excelentes estudos na área da história cultural, como Oktoberfest. Turismo, festa e cultura na estação do chopp, de Maria Bernadete Ramos Flores (Florianópolis: Letras Contemporâneas, 1997).

A determinação cultural dos agentes e das práticas sociais, para alćm da econômica e política, revela-se na leitura que os historiadores passam a fazer das subjetividades, do imaginário e do campo simbólico. Roger Chartier (1988) sistematiza as inovações trazidas por uma produção historiográfica que assume sua ruptura com a crença no real e no social. Para além da construção cultural de nossas referências, enfatiza as práticas 
de leitura e apropriação da cultura, destacando os complexos movimentos da circulação das idéias. ${ }^{9}$

No Brasil, o "brazilianista" Jeffrey D. Needell analisa a vida cultural das elites cariocas em Belle Époque tropical. Sociedade e cultura de elite no Rio de Janeiro na virada do século (Cia das Letras, 1993). Inovador quanto à temática, o livro desvenda as formas de sociabilidade, lazer e consumo de homens e mulheres das classes dominantes no século passado, dando especial ênfase à circulação das idéias, às reunióes literárias e a outras formas de produção e consumo cultural.

O historiador Alcir Lenharo, por sua vez, parte, em sua última obra, em busca das sociabilidades nômades nas noites boêmias do Rio de Janeiro, entre os anos 40 e 50 , onde se reuniam cantores, músicos, artistas, intelectuais e políticos. Cantores do rádio. A trajetória de Nora Ney e Jorge Goulart e o meio artistico de seu tempo (Editora da Unicamp, 1995) apresenta a história do rádio brasileiro a partir da biografia desses dois grandes cantores, notáveis não só pelo sucesso đe seu trabalho, mas pela militância política de esquerda. Todo um multifacetado e colorido universo cultural, artístico e musical emerge em torno desses conhecidos artistas do rádio, freqüentadores do mundo boêmio da Lapa, no Rio de Janeiro, ou em São Paulo. Leitor de Foucault, Deleuze e Guattari, o historiador preocupa-se, ainda, con os processos de desterritorialização e subjetivação mobilizados pela mídia na produção e circulação de signos, especialmente na estreita relação que se estabelece entre os artistas e seu público. Já o universo musical e suas relações com a sociedade, o Estado e a cultura, ao longo da história brasileira do período republicano, vem sendo preocupação do rico e minucioso trabalho do renomado historiador, Arnaldo Contier, cuja livre-docência deverá ser publicada em breve. ${ }^{10}$

Num outro pólo, em Trem fantasma (Cia das Letras, 1988), Francisco Foot Hardman focaliza, recorrendo fortemente a Walter Benjamin, o impacto da modernidade no momento de expansão da ferrovia no norte do País, nos inícios do século, no plano da transformação do imaginário social. Paulo Miceli, em $O$ ponto onde estamos. Viagens e viajantes na história da expansão e da conquista (Scritta, 1994), desmistifica o caráter heróico dos "grandes descobrimentos" realizados pelos navegadores portugueses durante o século XVI, apresentando o dificil e conflituoso cotidiano dos navios que para cá se dirigiam. Já em Imagens da colonização. A representação do indio de Caminha a Vieira (Zahar, 1996), Ronald Raminelli investiga as imagens e representações construidas sobre os/as indigenas pelo olhar dos viajantes, conquistadores e inquisidores europeus, a partir daquele século. Contrapondo discursos e 
iconografia, desvenda um universo extremamente contraditório e fantasioso de imagens projetadas sobre os nativos/as da terra, carregado de preconceitos eurocêntricos, misóginos e racistas. Mais do que nunca, a cultura substitui a sociedade como foco privilegiado de atenção do historiador. Ao mesmo tempo, a desconstrução é incorporada como estratégia de análise das configurações discursivas, permitindo descrever e nuançar as armadilhas presentes nos discursos históricos, que construíram as modernas referências da história brasileira.

\section{SALDOS, BALANÇOS E PERSPECTIVAS}

Passados os booms específicos, como muitos definem a descoberta de autores como Foucault, Thompson, Benjamin, Castoriadis, é possível perceber importantes saldos e incorporações. Em primeiro lugar, destaco a concepção de que a história é um discurso mais do que o encontro com os próprios fatos, de que constrói uma interpretação mais do que revela o que "realmente aconteceu" no passado. Nesse sentido, o historiador passa a operar com o discurso da história, considerado como estratégia discursiva, visando a seus alvos específicos, ao mesmo tempo em que já não parte dos objetos prontos, mas os constitui como efeitos de linguagem. O documento é buscado mais intensamente, ao mesmo tempo não mais como espelho do real, mas sim como monumento, possibilitando desfazer camadas sedimentadas de interpretações sucessivas.

A incorporação da subjetividade, como dimensão a ser historicizada e incorporada pelo pesquisador, resulta de uma profunda desconfiança na existência de uma realidade organizada, exterior, pronta para ser definitivamente decifrada. Trata-se agora de tematizar a mediação estabelecida entre o historiador e seu objeto, distinguindo ainda as formas de representação dos atores sociais e as do próprio estudioso. Nesta direção, mais do que a inclusão dos oprimidos na grande narrativa, processa-se um deslocamento epistemológico, a busca de novas linguagens e figuras que dêem conta de captar as diferenças. Quebra-se a lógica da identidade, a figura do sujeito universal, as categorias abstratas e universalizantes que contavam a história dos dominantes como se fora de todo um povo. Ao mesmo tempo, buscam-se novas formas narrativas, já que conteúdo e forma passam a adquirir status e relevo do mesmo nível.

Questiona-se acentuadamente a própria representação do passado, vista como fardo ou libertação. ${ }^{11}$ Pergunta-se: a que vem o conhecimento do passado? E ainda: de que passado precisamos? Cada vez mais, os 
historiadores aceitam a impossibilidade de se trabalhar com a noção de totalidade, a fragmentação impondo-se progressivamente com os novos processos da globalização, do crescimento da mídia e de presentificação da memória.

Algumas tendências destacam-se: a busca de uma releitura dos historiadores clássicos, tendo em vista desconstruir seu discurso, e não aprender a "realidade" que supostamente descrevem. Hoje lemos Paulo Prado, Gilberto Freyre, Sérgio Buarque de Holanda ou Caio Prado Júnior, considerados os "inventores do Brasil", nos anos 30, menos para conhecer o passado do que para entender como foi interpretado. Como se lia; que verdades foram produzidas a respeito de nossa identidade; como se escreveu a história da Nação; que mitos foram engendrados; que atores foram suprimidos; que verdades foram inventadas, a partir de determinados jogos de poder, e não reveladas como essências são algumas das perguntas correntes. Nesta linha de estudo, é de um antropólogo o principal trabalho sobre a cultura sexual brasileira: Corpos, prazeres e paixöes. A cultura sexual contemporânea no Brasil, de Richard Parker (Ed. BestSeller, 1991), que figura ao lado de algumas leituras psicanalíticas da historiografia brasileira, como Fantasias de Brasil, de Octávio de Souza (Escuta, 1994) e Hello, Brazil, de Contardo Calligaris.

É visivel, ainda, a preocupação em captar mais integralmente os fenômenos históricos e as ações individuais ou coletivas na trama de complexas relações sociais. Busca-se, portanto, integrar conceitos como gênero, raça e classe nos estudos específicos. Em relação à questão racial, destaca-se o impacto da historiografia norte-americana que, sem dúvida, força a discussão na área, ao lado do movimento negro em nosso País. Os "brazilianistas" insistem em questionar e denunciar o mito da "democracia racial" brasileira, inventado por Gilberto Freyre em Casa grande e senzala, de 1933. Apontam para a exclusão social e política dos negros, que constituen uma porcentagem extremamente alta da população brasileira, e que raramente aparecem nos estudos históricos, assim como na mídia, a não ser na condição de subalternos, escravos, empregadas domésticas, faxineiros, etc., cargos que desempenham na vida real, quando estão empregados. Vale aqui lembrar os estudos históricos de Robert Slenes (1994) sobre a família escrava, de Célia Marinho (1987) sobre o abolicionismo e de muitos outros preocupados em recuperar as inúmeras manifestações de resistência social dos escravos no Brasil.

No que se refere ao campo conceitual, nota-se ainda uma certa flexibilidade e ecletismo teórico: uma recusa a filiar-se estritamente a um campo conceitual, a mistura de conceitos como as "disciplinas" foucaul- 
tianas no marxismo, procedimentos da história cultural com história social. Aliás, a própria busca da interdisciplinaridade, com o aporte de diferentes áreas do conhecimento, como a psicanálise, a literatura, a antropologia, a arquitetura e a arte levam a uma redefinição dos modos de operação intelectual.

Grandes coletâneas são produzidas, destinadas a um grande público: a História das mulheres no Brasil, organizada por Mary del Priore e Carla Bassanezzi (Contexto, 1997), reunindo especialistas da área; a História da vida privada, (v. 1, 2, 3, Companhia das Letras, 1997), a primeira organizada por Fernando Novaes e Laura de Mello e Souza; c um livro de reflexão teónica e historiográfica, Domínios da história, dirigido por Ciro Flamarion Cardoso e Ronaldo Vainfas (Campus, 1997), também reunindo especialistas conhecidos. Em todos esses livros, nota-se ao mesmo tempo o esforço no sentido de avaliar os estudos históricos produzidos em cada área e de divulgar, para um público muito mais amplo e leigo, os resultados das pesquisas e livros realizados sobre temas especificos.

Outra tendência que se observa é a publicação de biografias e memórias. Alguns historiadores consagrados publicam, hoje, estudos de história que mesclam suas próprias memórias e experiências. É o caso de Negócios e ócios, de Boris Fausto (Companhia das Letras, 1997), um estudo da imigração judaica em São Paulo, que remete à sua vivência pessoal e familiar e que vem ampliar os estudos de imigração também trabalhados por um destacado "brazilianista" Jeffrey Lesser, em $A$ questão judaica no Brasil_ (Ed. Imago, 1995). Outros partem em busca das trajetórias individuais, preocupando-se, contudo, $\mathrm{cm}$ inserir as experiências de vida numa ampla e densa rede de relações sociais. Assim, Marina Maluf, em Ruidos da memória (1997), apresenta as transformações e a crise da aristocracia cafceira paulista a partir da leitura dos diários de mulhcres das elites, propiciando a leitura antropológica e feminina das transformações econômicas conhecidas anteriormente, especialmente a partir de obras como as do historiador marxista Caio Prado Júnior.

Menção deve ser feita, também, à recente área de estudos religiosos que vem ganhando inúmeras pesquisas e teses, a exemplo de Vida e morte: o homem no labirinto da eternidade (no prelo), de 1993, de Eliane Moura Silva, e O espiritualismo no século 19 (Editora do IFCH-Unicamp, 1997).

Dos trabalhos de jornalistas-historiadores, vale mencionar as obras de Fernando Moraes, autor de dois best-sellers no País: as biografias de Olga (Companhia das Letras, 1994), militante comunista alemã, companheira de Luís Carlos Prestes, executada em campo de concentração na Alemanha, e de Chateaubriand (Companhia das Letras, 1996), em- 
presário e político conhecido especialmente por sua atuação nos meios culturais dos anos 50 .

Em todos esses trabalhos, observa-se a preocupação com a escrita, com o estilo literário, com a construção de uma narrativa pessoal e emocionada, o que torna a leitura densa e muito agradável. Além disso, ao contrário de estudos biográficos anteriores, evita-se mistificar o personagem como figura heróica e fantástica, procurando-se construí-lo de uma maneira mais complexa e humana. Mais do que nunca, o oficio do historiador se amplia, aproximando-o de jornalistas e romancistas, em busca de um público-leitor que também já não se encontra puramente nas universidades e instituições acadêmicas. O historiador já não é a figura indiferente ao presente que traziam os romances do século XIX, mas um dos intérpretes do passado, pronto para ser ouvido em toda a parte com um novo guardião de memórias.

\section{NOTAS}

1. Veja-se o instigante trabalho de Burmester, Ana Maria de Oliveira. $A$ (desjconstrução do discurso histórico. A historiografia brasileira nos anos 70. Curitiba: Aos Quatro Ventos, 1997.

2. Vejam-se Marson, Isabel. O império do progresso: a Revolução Praieira em Pernambuco. São Paulo: Brasiliense,1987; Movimento Praieiro - imprensa, ideologia e poder político. São Paulo: Editora Moderna, 1980; Marson, Adalberto. A ideologia nacionalista em Alberto Torres. São Paulo: Duas Cidades, 1979; Contier, Arnaldo D. Ideologia e imprensa em São Paulo, 1822-1842: matrizes do vocabulário político e colonial. Petrópolis: Vozes, Campinas: Unicamp, 1979; Capelato, Maria Helena. Os arautos do liberalismo. São Paulo: Brasiliense, 1989.

3. Vejam-se Hobsbawm, Eric - Rebeldes Primitivos. Rio de Janeiro: Paz e Terra, 1975; Revolucionários. Rio de Janeiro: Paz e Terra, 1979.

4. Veja-se Margareth Rago: "O efeito-Foucault na Historiografia Brasileira." Tempo Social, Revista de Sociologia da USP, SP, 1995, v.7, n. 1-2, p.67-82.

5. Vejam-se as discussões de Costa, Jurandir Freire. O referente da identidade homossexual. In: Parker, Richard e Barbosa, Regina M. (orgs.). Sexualidades brasileiras. Rio de Janeiro: Rocco, 1996.

6. Veja-se, por exemplo, Knibiehler, Ivonne e Fouquet, Catherine. La Femme et les médecins. Paris: Hachette, 1983; Sant'Anna Denise Bernuzzi de(org.). Politicas do corpo. São Paulo: Estação Liberdade, 1995.

7. Veja-se Bresciani, Maria Stella. Londres e Paris: o espetáculo da pobreza. São Paulo: Brasiliense, 1986.

8. Refiro-me ao título do livro de Edgar de Decca, já citado. 
9. Veja-se Lajolo, Marisa e Zilberman, Regina. A formação da leitura no Brasil. São Paulo: Ática, 1996.

10. Veja-se Contier, Arnaldo D. Villa-Lobos e o Estado Novo: 1937-45 (anteprojeto: algumas reflexões), São Paulo, mimeo, 1987; Passarinhada do Brasil: canto orfeônico, educação e getulismo. Bauru, São Paulo: EDUSC, 1998.

11. Veja-se a respcito White, Hayden. O fardo da história. In: Trópicos_do_discurso. São Paulo: Edusp, 1993.

\section{REFERÊNCIAS BIBLIOGRÁFICAS}

ALVES, Branca Moreira. Ideologia e feminismo. A luta da mulher pelo voto no Brasil. Petrópolis: Vozes, 1980.

AZEVEDO, Célia Maria Marinho de. Onda negra, medo branco. O negro no imaginário das elites no século 19. Rio de Janeiro: Paz e Terra, 1987.

BENJAMIN, Walter. Discursos interrumpidos I. Madri: Taunus, 1982.

BURKE, Peter. A Escola dos Annales. São Paulo: Unesp, 1991.

CARVALHO, José Murilo de. Os bestializados. São Paulo: Companhia das Letras, 1988.

CASTORIADIS, Cornelius. A instituição imaginária da sociedade. Rio de Janeiro: Paz e Terra, 1986.

CHARTIER, Roger. $A$ história cultural entre práticas e representações. Lisboa: Difel, 1988.

DECCA, Edgar de. O silencio dos vencidos. São Paulo: Brasiliense, 1981.

DOSSE, François. A história em migalhas. São Paulo: Editora da Unicamp / Ensaio, 1992.

FOUCAULT, Michel. História da sexualidade v. 2 O uso dos prazeres. Rio de Janeiro: Graal, 1984.

HOLANDA, Sérgio Buarque. Raizes do Brasil. Rio de Janeiro: Editora José Olympio, 1994, 26.ed.; 1.ed., 1936.

MALUF, Marina. Ruidos da memória. São Paulo: Siciliano, 1995.

MATTOS, Maria Izilda S. e FARIA, Fernando A. de. Melodia e sintonia em Lupicinio Rodrigues: o feminino, o masculino e suas relações. Rio de Janeiro: Bertrand Brasil, 1996.

Dolores Duran. Rio de Janeiro: Bertrand Brasil, 1997.

MEZAN, Leila. Honradas e devotas, mulheres da colônia. Rio de Janeiro: José Olympio, 1993.

MOREIRALEITE, Miriam. Outra face do feminismo: Maria Lacerda de Moura. Rio de Janeiro: Ática, 1984.

PECHMAN, Sérgio e FRITISCH, Lilian. A reforma urbana e seu avesso: algumas considerações a propósito da modernização do Distrito Federal. Revis ta Brasileira de História, n.8-9, p.139-196, 1985.

PRIORE, Mary del. Ao sul do corpo. Condição feminina, maternidades e men- 
talidades no Brasil Colônia. Rio de Janeiro/Brasilia: José Olympio/EDU$\mathrm{NB}, 1993$.

RAGO, M. Epistemologia feminista, gênero e história. In: PEDRO, Joana e GROSSI, Miriam (orgs.). Masculino, feminino, plural. Florianópolis: Editora das Mulheres, 1998.

RAGO, Margareth. As mulheres na historiografia brasilcira. In: LOPES, Zélia (org.). A história em debate. São Paulo: Editora da UNESP, 1991.

SAMARA, Eni de Mesquita. As mulheres, o poder e a familia. São Paulo no século $X I X$. São Paulo: Marco Zero/SEEC, 1989.

SEVCENKO, Nicolau. Orfeu extático na metrópole. São Paulo: sociedade e cultura nos frementes anos 20. São Paulo: Companhia das Letras, 1992.

SLENES, Robert. Lares negros, olhares brancos. In: ARANTES, Antonio Augusto(org.). Colcha de retalhos. São Paulo: Editora da UNICAMP, 1994, 3.ed.

SOIHET, Raquel. Condição feminina e formas de violência - mulheres pobres e ordem urbana, 1870-1920. Rio de Janeiro: Forense, 1989.

STEPAN, Alfred (org.). Democratizando o Brasil. Rio de Janeiro: Ed. Paz e Terra, 1988.

SWAIN, Tânia Navarro. Feminino/masculino no Brasil do século XVT: um estudo historiográfico, 1995, (mimeo).

THOMPSON, E. P. "Tiempo, Disciplina y Capitalismo Industrial”. In: Tradición, revuelta y consciencia de clase. Barcelona: Editorial Critica, 1979.

THOMPSON, E. P. Formação da classe trabalhadora na Inglaterra. Rio de Janeiro: Editora Paz e Terra, Oficina de História, 1988. 